\title{
Salvage Concurrent Chemo-radiation Therapy for Loco-regional Recurrence Following Curative Surgery of Non-small Cell Lung Cancer
}

\author{
Kyung Hwa Lee, MD \\ Yong Chan Ahn, MD, PhD' \\ Hongryull Pyo, MD, PhD' \\ Jae Myoung Noh, MD, PhD' \\ Seung Gyu Park, MD 1 \\ Tae Gyu Kim, MD2 \\ Eonju Lee, MD² \\ Heerim Nam, MD, PhD ${ }^{3}$ \\ Hyebin Lee, $\mathrm{MD}^{3}$ \\ Jong-Mu Sun, MD, PhD ${ }^{4}$ \\ Jin Seok Ahn, MD, PhD ${ }^{4}$ \\ Myung-Ju Ahn, MD, PhD ${ }^{4}$ \\ Keunchil Park, MD, $\mathrm{PhD}^{4}$
}

\begin{abstract}
${ }^{1}$ Department of Radiation Oncology, Samsung Medical Center, Sungkyunkwan University School of Medicine, Seoul, ${ }^{2}$ Department of Radiation Oncology, Samsung Changwon Hospital, Sungkyunkwan University School of Medicine, Changwon, ${ }^{3}$ Department of Radiation Oncology, Kangbuk Samsung Hospital, Sungkyunkwan University School of Medicine, Seoul, ${ }^{4}$ Division of Hematology-Oncology, Samsung Medical Center, Sungkyunkwan University School of Medicine, Seoul, Korea
\end{abstract}

\section{Purpose}

This study is to report clinical outcomes of salvage concurrent chemo-radiation therapy (CCRT) in treating patients with loco-regional recurrence (LRR) following initial complete resection of non-small cell lung cancer.

\section{Materials and Methods}

Between February 2004 and December 2016, 127 patients underwent salvage CCRT for LRR. The median radiation therapy (RT) dose was 66 Gy and clinical target volume (CTV) was to cover recurrent lesion with margin without elective inclusion of regional lymphatics. Majority of patients $(94.5 \%)$ received weekly platinum-based doublet chemotherapy during RT course.

\section{Results}

The median follow-up time from the start of CCRT was 25 months. The median survival duration was 49 months, and overall survival (OS) rates at 2 and 5 years were $72.9 \%$ and 43.9\%. The 2- and 5-year rates of in-field failure-free survival, distant metastasis free survival, and progression free survival were $82.4 \%$ and $73.8 \%, 50.4 \%$ and $39.9 \%$, and $34.6 \%$ and $22.3 \%$, respectively. Grade $\geq 3$ radiation-related esophagitis and pneumonitis occurred in $14(11.0 \%)$ and six patients (4.7\%), respectively. On both univariate and multivariate analysis, higher biologically equivalent dose $\left(\mathrm{BED}_{10}\right)\left(\geq 79.2 \mathrm{~Gy}_{10}\right.$ vs. $<79.2 \mathrm{~Gy}_{10}$; hazard ratio [HR], 0.431), smaller CTV ( $\leq 80 \mathrm{~cm}^{3}$ vs. $>80 \mathrm{~cm}^{3} ; \mathrm{HR}, 0.403$ ), and longer disease-free interval (> 1 year vs. $\leq 1$ year; HR, 0.489) were significantly favorable factors for OS.

\section{Conclusion}

The current study has demonstrated that high dose salvage CCRT focused to the involved lesion only was highly effective and safe. In particular, higher $\mathrm{BED}_{10}$, smaller CTV, and longer disease-free interval were favorable factors for improved survival.

\section{Key words}

Non-small cell lung carcinoma, Loco-regional recurrence, Salvage concurrent chemo-radiation therapy

\author{
Correspondence: Yong Chan Ahn, MD, PhD \\ Department of Radiation Oncology, Samsung \\ Medical Center, Sungkyunkwan University \\ School of Medicine, 81 Irwon-ro, Gangnam-gu, \\ Seoul 06351, Korea \\ Tel: $82-2-3410-2602$ \\ Fax: 82-2-3410-2619 \\ E-mail: ahnyc@skku.edu \\ Received June 17, 2018 \\ Accepted September 5, 2018 \\ Published Online September 11, 2018
}




\section{Introduction}

Lung cancer is the worldwide leading cause of cancer death and the same is applied to Korea [1,2]. Even with remarkable advancement in radiation therapy (RT) techniques and chemotherapy regimens, surgical resection still remains the choice of treatment for resectable non-small cell lung cancer (NSCLC) patients. However, the recurrence rates even following apparently complete curative resection have been reported as $25 \%-51 \%$ [3-7]. The post-recurrence prognosis has been generally poor, and the median survival duration following recurrence has been reported as 8.1-21 months in the previous literatures [4-6,8], which largely depends on the recurrence site and subsequent therapeutic approach $[8,9]$. In case of loco-regional recurrence (LRR), the local treatment modality including re-operation or high dose RT with or without concurrent chemotherapy would be considered, which could lead to for survival with local cure.

There have been a few studies on aggressive re-operation for resectable LRR or new primary lung cancer, most of which reported promising survival outcomes $[10,11]$. Reoperation, however, can usually be limited only to the patients with adequate cardio-pulmonary functional reserves considering the risk of surgical morbidity and motality. The alternative option is high dose RT with or without concurrent chemotherapy. Several studies on salvage RT for LRR reported the rates of overall survival (OS) at 2 years ranging from $30 \%$ to $62.4 \%$ and the median survival ranging from 14 to 54.8 months [12-19]. Most of these studies included relatively small number of patients, with insufficient follow-up period. Their survival outcomes, however, were comparable to or even better than those of the patients who received radical $\mathrm{RT}$ as the initial therapy [20-22]. In addition, Bae et al. [15] previously demonstrated that the use of concurrent chemoradiation therapy (CCRT) was more favorable for OS over RT alone. Some other investigators also reported that salvage CCRT in treating the patients with LRR was promising $[16,18]$. We would report the clinical outcomes and toxicity profiles following exclusively salvage CCRT in treating the patients who developed LRR following the initial curative complete resection.

\section{Materials and Methods}

\section{Patients}

We retrospectively reviewed the medical records of all patients who underwent salvage CCRT in the authors' hos- pitals between February 2004 and December 2016 for LRR of NSCLC following surgery. The decision on chemoradiotherapy, instead of surgical resection, was made through the multidisciplinary conference discussion, and all patients were presumed to have had high risk by reoperation considering the patients' condition, expected difficulty of resection, and risk of post-surgical morbidity. The inclusion criteria were (1) initial complete resection with or without adjuvant chemotherapy but without adjuvant RT, (2) no evidence of distant metastasis, and (3) CCRT with curative aim.

The suspicion and diagnosis of LRR was made in 127 patients, based on enlarging or new lesion on two or more consecutive chest computed tomography (CT), coupled with increased fluoro-deoxy-glucose uptake on positron emission tomography-computed tomography (PET-CT). In principle, the diagnosis of LRR was to be made by cytopathological confirmation whenever possible, either by bronchoscopic or endobronchial ultrasound-guided needle biopsy and/or aspiration cytology, which was feasible in 80 patients (63.0\%).

\section{Treatment}

RT was given using 4-, 6-, or 10-MV photon beams from linear accelerators. The clinical target volume (CTV) was to cover the recurrent gross lesion(s) only with 5-10 mm margin in all directions but not to cover the regional lymphatics electively. Three-dimensional conformal RT using 3-4 beams was mainly used in 118 patients $(92.9 \%$ ) and intensity-modulated RT was used in nine $(7.1 \%)$, who had relatively large CTV or poor lung function. The typical planned dose schedule was to deliver $66 \mathrm{~Gy}$ in 33 fractions, and the median total dose actually delivered was 66 Gy (range, 37 to 70 Gy). The median total dose converted into biologically equivalent dose $\left(\mathrm{BED}_{10}\right)$ was $79.2 \mathrm{~Gy}_{10}$ (range, 44.9 to $84.8 \mathrm{~Gy}_{10}$ ).

Majority of patients $(94.5 \%)$ were treated with weekly platinum-based doublet chemotherapy during the RT course and the chemotherapy regimens were weekly paclitaxel plus cisplatin in 68 patients $(53.5 \%)$, weekly docetaxel plus cisplatin in $49(38.6 \%)$, 3-weekly etoposide plus cisplatin in seven $(5.5 \%)$, and weekly paclitaxel plus carboplatin in three (2.4\%), respectively. The median number of weekly chemotherapy cycles was six (range, 2 to 7 ).

\section{Endpoints and statistical analysis}

The failure patterns following salvage CCRT were subdivided into in-field failure (IFF), out-of-field regional failure, and distant metastasis (DM): IFF was defined as the failure within the radiation field; out-of-field regional failure was defined as the failure in regional area out of radiation field; and DM was defined as failure in distant organs including parenchymal pulmonary metastasis, respectively. The end- 
points included the rates of IFF-free survival (IFFFS), locoregional failure-free survival (LRFFS), DM-free survival (DMFS), progression-free survival (PFS), and OS. The durations of IFFFS, LRFFS, DMFS, PFS, and OS were calculated from the date of start of RT to the date of the recurrence, death, or the last follow-up.

The chi-square test and test were used to analyze the distributions of categorical and continuous variables, respectively. The Kaplan-Meier method was used to determine the survival rate. The log-rank test was used to compare the differences between the groups, and the Cox proportional hazards regression model was used for multivariate analysis. A p-value less than 0.05 was considered statistically significant and the software SPSS ver. 23.0 (IBM Corp., Armonk, NY) was used for the statistical analysis.

\section{Ethical statement}

This study was approved by the Samsung Medical Center Institutional Review Board (2018-03-160), and conducted in accordance with the principles of the Declaration of Helsinki. The informed consent was waived.

\section{Results}

\section{Patients' characteristics}

The patients' characteristics are summarized in Table 1. The median age was 63 years (range, 37 to 79 years), and $79.5 \%$ of patients were male. Eastern Cooperative Oncology Group performance scores were 0 in 30 patients (23.6\%), one in $91(71.7 \%)$, and two in six $(4.7 \%)$, respectively. The initial types of surgery were pneumonectomy in 11 patients $(8.7 \%)$, lobectomy in $110(86.6 \%)$, and sublobar resection in six $(4.7 \%)$, respectively. The pathologic stages following the initial surgery according to American Joint Cancer Committee (AJCC) eighth stages were I in 37 patients (29.1\%), II in 49 $(38.6 \%)$, IIIa in $33(26.0 \%)$, IIIb-c in five $(3.9 \%)$, and unknown in three $(2.4 \%)$, who underwent the initial surgery at other hospital, respectively. Adenocarcinoma and squamous cell carcinoma were the most common histological types observed in $72(56.7 \%)$ and 48 patients (37.8\%), respectively, and others were pleomorphic carcinoma in four, large cell carcinoma in one, adeno-squamous cell carcinoma in one, and combined squamous cell carcinoma with large cell carcinoma in one, respectively. The median disease-free interval (DFI), defined as the time from the initial surgery till the start of salvage CCRT was 15 months (range, 1 to 80 months). LRR following the initial surgery was subdivided into local,
Table 1. Patients' characteristics

\begin{tabular}{|cc|}
\hline Variable & No. of patients \\
\hline Age (yr) & $63(37-79)$ \\
\hline Sex & $101(79.5)$ \\
\hline Male & $26(20.5)$ \\
\hline Female & \\
\hline ECOG performance status & $30(23.6)$ \\
\hline 0 & $91(71.7)$ \\
\hline 1 & $6(4.7)$ \\
\hline 2 & \\
\hline Initial type of surgery & $11(8.7)$ \\
\hline Pneumonectomy & $110(86.6)$ \\
\hline Lobectomy & $6(4.7)$ \\
\hline Sublobar resection & \\
\hline Initial pathologic stage $\left.{ }^{a}\right)$ & $37(29.1)$ \\
\hline I & $49(38.6)$ \\
\hline II & $33(26.0)$ \\
\hline IIIa & $5(3.9)$ \\
\hline IIIb-c & $3(2.4)$ \\
\hline Unknown & \\
\hline Histology & $72(56.7)$ \\
\hline Adenocarcinoma & $48(37.8)$ \\
\hline Squamous cell carcinoma & $7(5.5)$ \\
\hline Others & \\
\hline Recurrent stage $\left.{ }^{a}\right)$ & $9(7.1)$ \\
\hline rI & $12(9.4)$ \\
\hline rII & $57(44.9)$ \\
\hline rIIIa & $49(38.6)$ \\
\hline rIIIb-c & $54(42.5)$ \\
\hline Disease-free interval (yr) & \\
\hline$>1$ & \\
\hline$\leq 1$ & \\
\hline & \\
\hline
\end{tabular}

Values are presented as median (range) or number $(\%)$. ECOG, Eastern Cooperative Oncology Group. ${ }^{a}$ Stage according to American Joint Cancer Committee eighth edition.

defined as the recurrence within or around the primary tumor, regional, as the recurrence within regional lymphatics, and loco-regional, as the recurrence including both local and regional recurrence components, respectively. The patterns of LRR were local in 21 patients $(16.5 \%)$, regional in 81 $(63.8 \%)$, and loco-regional in $25(19.7 \%)$, respectively. All patients were re-staged as if they had been newly diagnosed as having NSCLC according to the AJCC eighth stage, and the recurrent stages were $\mathrm{rI}$ in nine patients $(7.1 \%), \mathrm{rII}$ in 12 $(9.4 \%)$, rIIIa in $57(44.9 \%)$, rIIIb in $48(37.8 \%)$, and rIIIc in one $(0.8 \%)$, respectively. 


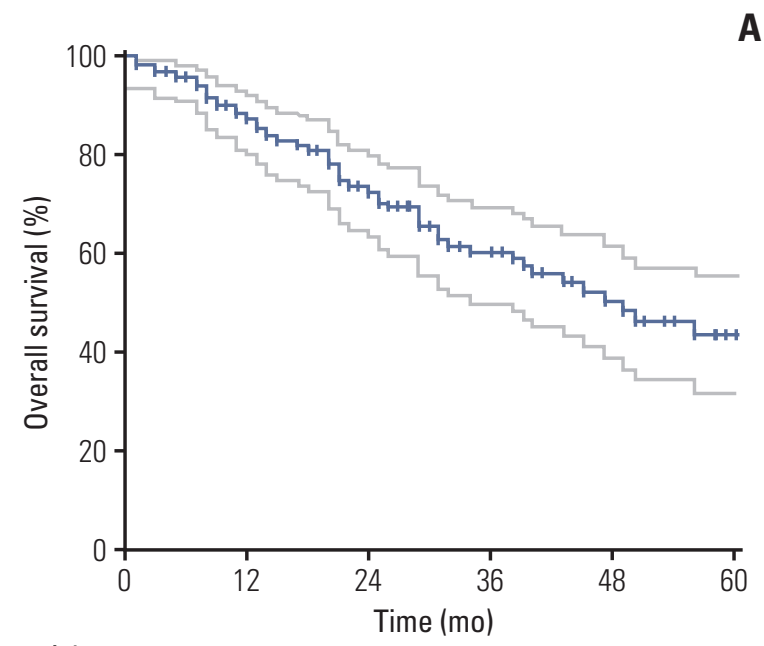

No. at risk

$\begin{array}{llllll}127 & 100 & 66 & 44 & 26 & 15\end{array}$

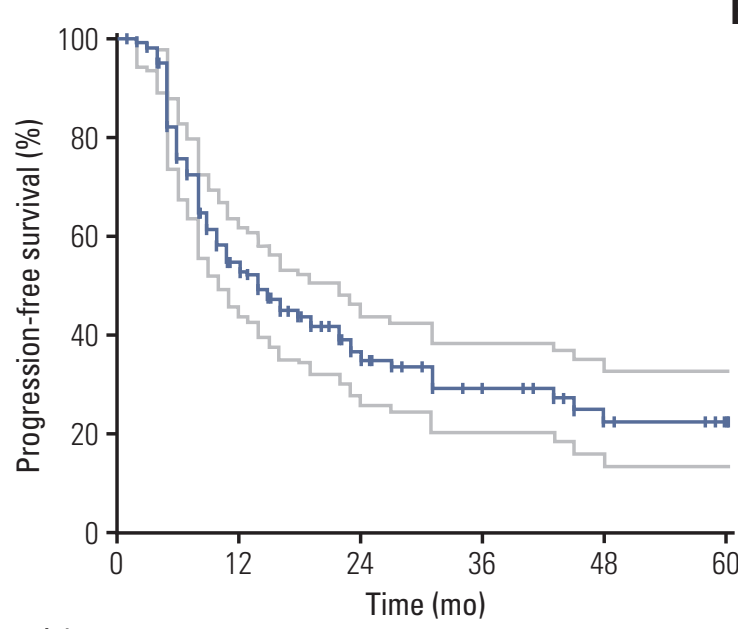

No. at risk

$\begin{array}{llllll}127 & 59 & 31 & 20 & 10 & 6\end{array}$

Fig. 1. Kaplan-Meier plots of overall survival (A) and progression free survival (B).

\section{Survival outcomes}

The median follow-up time from the start of salvage CCRT in all patients was 25.0 months (range, 1 to 112 months). The median survival duration was 49 months and the 2- and 5-year OS rates were $72.9 \%$ and $43.9 \%$, respectively (Fig. 1A). On the univariate analysis, the favorable factors with OS were DFI longer than 1 year $(p=0.009), B_{10}$ higher than 79.2 Gy10 $(p=0.012)$, and CTV smaller than $80 \mathrm{~cm}^{3}(\mathrm{p}=0.001)$, respectively (Table 2 ). Multivariate Cox regression analysis of the possible favorable prognostic factors for OS were higher $\mathrm{BED}_{10}$ ( $\geq 79.2$ Gy10 vs. < 79.2 Gy10; hazard ratio [HR], $0.431 ; 95 \%$ confidence interval [CI], 0.238 to $0.781 ; \mathrm{p}=0.005)$, smaller CTV ( $\leq 80 \mathrm{~cm}^{3}$ vs. $>80 \mathrm{~cm}^{3} ; \mathrm{HR}, 0.403 ; 95 \% \mathrm{CI}, 0.215$ to $0.755 ; \mathrm{p}=0.005$ ), and longer $\mathrm{DFI}$ ( $>1$ year vs. $\leq 1$ year; $\mathrm{HR}$ $0.489 ; 95 \% \mathrm{CI}, 0.277$ to $0.864 ; \mathrm{p}=0.014$ ), respectively.

\section{Failure pattetns following salvage CCRT}

The 2- and 5-year rates of IFFFS, LRFFS, DMFS, and PFS were $82.4 \%$ and $73.8 \%, 59.8 \%$ and $51.4 \%, 50.4 \%$ and $39.9 \%$, and $34.6 \%$ and $22.3 \%$, respectively (Fig. 1B). Eighty patients $(63.0 \%)$ experienced further recurrence following salvage CCRT. Fig. 2 presents failure patterns in relation to RT target volume. Twenty patients $(15.7 \%)$ developed IFF; $38(29.9 \%)$ did out-of-field regional failure; and 60 (47.2\%) did DM, respectively. The $\mathrm{BED}_{10}$ higher than $79.2 \mathrm{~Gy}_{10}$ was the only statistically significant factor for PFS $(p=0.043)$ on the univariate analysis (Table 2 ), and showed marginal significance on multivariate Cox regression analysis ( $\geq 79.2$ Gy10 vs. $<79.2$
Gy10; HR, 0.597; 95\% CI, 0.354 to $1.005 ; \mathrm{p}=0.052)$.

\section{Toxicity}

Though seven patients (5.5\%) could not complete the initially planned treatment mostly due to appearance of unexpected acute events including esophagitis, pneumonia, and worsening general condition, there was no incidence of grade 4 or 5 toxicity, and most patients tolerated salvage CCRT very well. The radiation-induced esophagitis was the most common acute toxicity and grade 2-3 esophagitis occurred in $57(44.9 \%)$ and 14 patients $(11.0 \%)$, respectively. Grade 2 and 3 delayed radiation pneumonitis occurred in eight $(6.3 \%)$ and six patients $(4.7 \%)$, respecetively. Other rare toxicities included grade 2-3 radiation dermititis in four $(3.2 \%)$ and grade 3 bronchial obstruction in one $(0.8 \%)$, respectively (Table 3).

\section{Discussion}

In treating the patients with locally advanced NSCLC, the fact that CCRT could significantly improve OS and PFS, when compared to RT alone, has been confirmed by several randomized trials and systematic reviews [20,21]. Meanwhile, it has not been properly studied whether OS benefit can be achieved by CCRT when compared with RT alone in salvage therapy setting. Instead, there have been a few stud- 
Table 2. Prognostic factors for 2-year rates of OS and PFS

\begin{tabular}{|c|c|c|c|c|c|}
\hline & No. of patients & 2-Year OS (\%) & p-value & 2-Year PFS (\%) & p-value \\
\hline \multicolumn{6}{|l|}{ Age (yr) } \\
\hline$\leq 63$ & 64 & 72.9 & 0.392 & 29.8 & 0.164 \\
\hline$>63$ & 63 & 73.1 & & 39.6 & \\
\hline \multicolumn{6}{|l|}{ Sex } \\
\hline Male & 101 & 73.8 & 0.784 & 36.1 & 0.233 \\
\hline Female & 26 & 69.6 & & 29.8 & \\
\hline \multicolumn{6}{|c|}{ ECOG performance status } \\
\hline 0 & 30 & 88.5 & 0.161 & 31.3 & 0.529 \\
\hline 1 & 91 & 68.0 & & 35.2 & \\
\hline 2 & 6 & 66.7 & & 50.0 & \\
\hline \multicolumn{6}{|l|}{ Initial type of surgery } \\
\hline Pneumonectomy & 11 & 54.5 & 0.477 & 55.6 & 0.106 \\
\hline Lobectomy & 110 & 73.7 & & 31.2 & \\
\hline Sublobar resection & 6 & 100 & & 55.6 & \\
\hline \multicolumn{6}{|c|}{ Initial pathologic stage ${ }^{a)}$} \\
\hline I & 37 & 71.2 & 0.876 & 28.0 & 0.876 \\
\hline II & 49 & 77.3 & & 32.8 & \\
\hline IIIa-c & 38 & 64.6 & & 43.5 & \\
\hline Unknown & 3 & - & & - & \\
\hline \multicolumn{6}{|l|}{ Recurrent stage ${ }^{a)}$} \\
\hline $\mathrm{rI}$ & 9 & 50.8 & 0.241 & 22.5 & 0.137 \\
\hline rII & 12 & 88.9 & & 56.6 & \\
\hline rIIIa & 57 & 77.5 & & 38.0 & \\
\hline rIIIlb-c & 49 & 67.5 & & 28.0 & \\
\hline \multicolumn{6}{|c|}{ Disease-free interval (yr) } \\
\hline$>1$ & 73 & 81.3 & 0.009 & 37.1 & 0.751 \\
\hline$\leq 1$ & 54 & 62.4 & & 31.4 & \\
\hline \multicolumn{6}{|l|}{ BED $_{10}(\mathrm{~Gy})$} \\
\hline$<79.2$ & 25 & 57.6 & 0.012 & 10.4 & 0.043 \\
\hline$\geq 79.2$ & 102 & 76.7 & & 40.8 & \\
\hline \multicolumn{6}{|c|}{ Clinical target volume $\left(\mathrm{cm}^{3}\right)$} \\
\hline$\leq 80$ & 60 & 84.3 & 0.001 & 33.7 & 0.862 \\
\hline$>80$ & 67 & 63.3 & & 35.2 & \\
\hline
\end{tabular}

OS, overall survival; PFS, progression-free survival; ECOG, Eastern Cooperative Oncology Group; BED, biologically equivalent dose. ${ }^{\text {a) }}$ Stage according to American Joint Cancer Committee eighth staging system.

ies, which advocated CCRT over RT alone by demonstrating improved clinical outcomes [15-16,18]. Bae et al. [15] of authors' institution previously reported the clinical outcomes of patients with LRR who received salvage RT, in which the proportion of patients receiving concurrent chemotherapy was only $21.9 \%$. The 2-year rates of IFFFS and OS were $52.3 \%$ and $47.9 \%$, respectively, and it was shown that CCRT could improve the 2-year OS rate significantly when compared with RT alone $(65.2 \%$ vs. $43.5 \%, \mathrm{p}=0.029$ by univariate analysis, and $\mathrm{p}=0.038$ by multivariate analysis). The present study which focused only to the 127 patients treated with CCRT, of the largest in number until as of yet, indicated that impro- ved clinical outcomes (the 2-year rates of IFFFS and OS of $82.4 \%$ and $72.9 \%$, respectively), when compared with the previous reports (Table 4 ).

Bae et al. [15] also pointed out that the use of PET-CT in diagnosing LRR, though not statistically significant, could reduce the time delay before treatment initiation and subsequently improve survival. PET-CT is well known to have improved the accuracy of diagnosis and stage assignment and subsequently clinical outcomes by assissting the therapeutic decision in lung cancer [22-25]. Jimenez-Bonilla et al. [26] also reported that PET-CT was highly accurate in detection of LRR and favorably affected survival. In this study, 


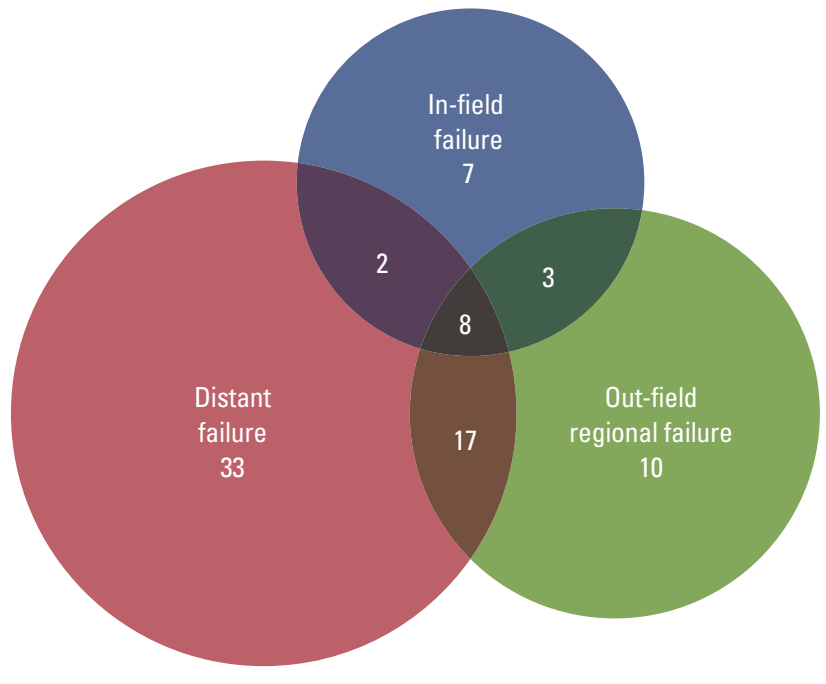

Fig. 2. Failure patterns in relation to radiation therapy target volume.

though cyto-pathological confirmation of LRR was feasible in less than two-thirds of the patients $(63.0 \%)$, all patients were diagnosed as having LRR based on the serial CT changes coupled with abnormality on PET-CT. Furthermore, most patients after salvage CCRT, were monitored with chest CT and PET-CT, which might have allowed early detection of further relapse and rapid decision making for the subsequent salvage effort. The improved clinical outcomes in the current study could have resulted from the broad use of PETCT as well as efficacy of CCRT.

In patients with pathologic III and margin negative NSCLC, adjuvant chemotherapy has been the standard treatment option. Especially in pathological N2 patients, sequential chemoradiation therapy could be recommended to improve locoregional control. However, adjuvant chemotherapy or RT is often omitted if the patients were with poor postsurgical condition or at old age, considering the increased risk of morbidity. In this study, all patients who developed locoregional recurrence following adjuvant RT following surgery were excluded, and among 38 patients who were with initial pathologic stage III, eight $(21.1 \%)$ did not receive adjuvant chemotherapy. The reasons for not receiving chemotherapy, regardless of post-surgical recommendation, included the physicians' choice considering the patients' condition or age and the patients' refusal. Considering very poor post-recurrence prognosis in this group, the current study indicated that salvage CCRT, as the second cura-

Table 3. Treatment-related toxicity

\begin{tabular}{lccc} 
Adverse event & Gr 0/1 & Gr 2 & Gr 3 \\
Acute radiation-induced esophagitis & $56(44.1)$ & $57(44.9)$ & $14(11.0)$ \\
Radiation pneumonitis & $113(89.0)$ & $8(6.3)$ & $6(4.7)$ \\
Radiation dermatitis & $7(5.5)$ & $3(2.4)$ & $1(0.8)$ \\
Bronchial obstruction & 0 & 0 & $1(0.8)$ \\
\hline
\end{tabular}

Values are presented as number $(\%)$.

Table 4. Results of salvage radiation therapy (RT) for loco-regional recurrent non-small cell lung cancer

\begin{tabular}{|c|c|c|c|c|c|c|}
\hline Study & Period & No. & $\begin{array}{l}\text { RT dose, } \\
\text { median } \\
\text { (range, Gy) }\end{array}$ & $\begin{array}{c}\text { Proportion of } \\
\text { patients receiving } \\
\text { CCRT }(\%)\end{array}$ & OS at 2 yr (\%) & $\begin{array}{l}\text { Median } \\
\text { OS (mo) }\end{array}$ \\
\hline Kelsey et al. [12] & 1991-2003 & 29 & $66(46-74)$ & 51.7 & 38 & 17 \\
\hline Tada et al. [13] & 1992-2002 & 31 & 60 & 16.1 & 30 & 14 \\
\hline Cai et al. [14] & 1992-2004 & 54 & $>59.4$ & 47.8 & 14.8 (at $5 \mathrm{yr}$ ) & 19.8 \\
\hline Bae et al. [15] & 1994-2007 & 64 & $54(44-66)$ & 21.9 & 47.9 & 18.5 \\
\hline Bar et al. [16] & 1999-2009 & 30 & $63.5(26-66)$ & 100 & 50.8 & 26.9 \\
\hline Lee et al. [17] & 2001-2009 & 38 & $60(45-75)$ & 31.6 & 56 & 27.9 \\
\hline Kim et al. [18] & 2004-2014 & 57 & $66(45-70)$ & 73.7 & 62.4 & 54.8 \\
\hline Seol et al. [19] & 2008-2013 & 31 & $66(51-66)$ & 51.6 & 58.4 & 14 \\
\hline Current study & 2004-2016 & 127 & $66(37-70)$ & 100 & 72.9 & 49 \\
\hline
\end{tabular}

CCRT, concurrent chemo-radiation therapy; OS, overall survival. 
tive attempt, could result in the improved survival outcome.

It is well known that the probability of local control and morbidity following RT mostly depens on the sensitivity to radiation, disease extent represented as the CTV, and its location in relation to the surrounding dose-limiting organs [27-30]. Lee et al. [17] reported that the gross tumor volume (GTV) was a prognostic factor for survival: the patients with GTV $<20 \mathrm{~cm}^{3}$ had significantly higher OS rates than those with GTV $>80 \mathrm{~cm}^{3}$. The size of recurrent lymph node by Seol et al. [19] and the single site recurrence by Kim et al. [18] were also proposed as the favorable factors for OS. In the current study, CTV $<80 \mathrm{~cm}^{3}$ was proved a favorable factor for OS by both univariate and multivariate analyses. Though it is not easy to define the cut-off value on the GTV, it has been re-confirmed that the small disease extent is favorable factor following CCRT in the current study.

Synergy by concurrent delivery of radiation with chemotherapy is capable of achieving high rate of local control, however, should be cautiously used because of more frequent and severe toxicity profiles, when compared with single modality alone. The systematic reviews on CCRT in locally advanced NSCLC reported more treatment-related deaths (4\% vs. $2 \%$ ) and significantly more common severe esophagitis (risk ratio, 4.96; 95\% CI, 2.17 to 11.37) following CCRT [21]. In this study, radiation target volume was to cover the recurrent lesions only with margin without elective nodal irradiation considering the toxicities to adjacent organs. Loco-regional failures developed in 47 patients $(37 \%)$, and 2-year rates of PFS and LRFFS were $34.6 \%$ and $59.8 \%$, respectively. These profiles were comparable with those of the prior studies that reported 2- or 3-year rates of
PFS ranging from $33.6 \%$ to $44.9 \%$, and LRFFS from $57.6 \%$ to $70.9 \%[17,18]$. Meanwhile, there was occurrence of neither severe chronic toxicity nor treatment-related death. The most commonly reported complications in salvage treatment setting are radiation-induced esophagitis and pneumonitis. The incidences of radiation-induced esophagitis and pneumonitis of Common Terminology Criteria for Adverse Event (CTCAE) grade $\geq 2$ were reported in the range of $28.9 \%-41.9 \%$ and $16.1 \%-24.6 \%$ [17-19] in the previous studies. In the present study, the incidence of acute radiation-induced esophagitis of CTCAE grade $\geq 2$ was relatively high as $55.9 \%$, which might be affected by that all patients in this study had been treated with CCRT. However, that of grade $\geq 3$ was $11.0 \%$, which was comparable with others $(0 \%-16.7 \%)$ [15-19]. The incidence of radiation pneumonitis of CTCAE grade $\geq 2$ in the current study was $11.0 \%$ and was comparable those of other studies. Based on these toxicity profiles, salvage CCRT, with the policy of limited target volume, were judged quite tolerable. However, efforts to further reduce the toxicity risk might be warranted, considering most patients might already have impaired lung function and performance status following the initial surgery.

In conclusion, the current study has demonstrated that high dose salvage CCRT focused to the involved lesion only was highly effective and safe. In particular higher BED ${ }_{10}$, smaller CTV, and longer DFI were favorable factors for improved survival.

\section{Conflicts of Interest}

Conflict of interest relevant to this article was not reported.

\section{References}

1. Ferlay J, Soerjomataram I, Dikshit R, Eser S, Mathers C, Rebelo $\mathrm{M}$, et al. Cancer incidence and mortality worldwide: sources, methods and major patterns in GLOBOCAN 2012. Int J Cancer. 2015;136:E359-86.

2. Jung KW, Won YJ, Oh CM, Kong HJ, Lee DH, Lee KH, et al. Cancer statistics in Korea: incidence, mortality, survival, and prevalence in 2014. Cancer Res Treat. 2017;49:292-305.

3. al-Kattan K, Sepsas E, Fountain SW, Townsend ER. Disease recurrence after resection for stage I lung cancer. Eur J Cardiothorac Surg. 1997;12:380-4.

4. Williams BA, Sugimura H, Endo C, Nichols FC, Cassivi SD, Allen MS, et al. Predicting postrecurrence survival among completely resected nonsmall-cell lung cancer patients. Ann Thorac Surg. 2006;81:1021-7.

5. Sugimura H, Nichols FC, Yang P, Allen MS, Cassivi SD, Deschamps C, et al. Survival after recurrent nonsmall-cell lung cancer after complete pulmonary resection. Ann Thorac Surg. 2007;83:409-17.

6. Saisho S, Yasuda K, Maeda A, Yukawa T, Okita R, Hirami Y, et al. Post-recurrence survival of patients with non-small-cell lung cancer after curative resection with or without induction / adjuvant chemotherapy. Interact Cardiovasc Thorac Surg. 2013;16:166-72.

7. Lee J, Kim HK, Park BJ, Cho JH, Choi YS, Zo JI, et al. Recurrence dynamics after trimodality therapy (Neoadjuvant concurrent chemoradiotherapy and surgery) in patients with stage IIIA (N2) lung cancer. Lung Cancer. 2018;115:89-96.

8. Sonobe M, Yamada T, Sato M, Menju T, Aoyama A, Sato T, et al. Identification of subsets of patients with favorable prognosis after recurrence in completely resected non-small cell lung cancer. Ann Surg Oncol. 2014;21:2546-54.

9. Yano T, Okamoto T, Fukuyama S, Maehara Y. Therapeutic 
strategy for postoperative recurrence in patients with nonsmall cell lung cancer. World J Clin Oncol. 2014;5:1048-54.

10. Terzi A, Lonardoni A, Falezza G, Scanagatta P, Santo A, Furlan $\mathrm{G}$, et al. Completion pneumonectomy for non-small cell lung cancer: experience with 59 cases. Eur J Cardiothorac Surg. 2002;22:30-4.

11. Kim HS, I H, Choi YS, Kim K, Shim YM, Kim J. Surgical resection of recurrent lung cancer in patients following curative resection. J Korean Med Sci. 2006;21:224-8.

12. Kelsey CR, Clough RW, Marks LB. Local recurrence following initial resection of NSCLC: salvage is possible with radiation therapy. Cancer J. 2006;12:283-8.

13. Tada T, Fukuda H, Nakagawa K, Matsui K, Hosono M, Takada $\mathrm{Y}$, et al. Non-small cell lung cancer: radiation therapy for locoregional recurrence after complete resection. Int J Clin Oncol. 2005;10:425-8.

14. Cai XW, Xu LY, Wang L, Hayman JA, Chang AC, Pickens A, et al. Comparative survival in patients with postresection recurrent versus newly diagnosed non-small-cell lung cancer treated with radiotherapy. Int J Radiat Oncol Biol Phys. 2010;76:1100-5.

15. Bae SH, Ahn YC, Nam H, Park HC, Pyo HR, Shim YM, et al. High dose involved field radiation therapy as salvage for locoregional recurrence of non-small cell lung cancer. Yonsei Med J. 2012;53:1120-7.

16. Bar J, Ng D, Moretto P, Goss GD, Sun A, Macrae R, et al. Chemoradiotherapy for locoregional recurrence of non-smallcell lung cancer after surgical resection: a retrospective analysis. Clin Lung Cancer. 2013;14:200-4.

17. Lee NK, Moon SH, Kim TH, Han JY, Yun T, Kim HT, et al. Prognostic value of gross tumor volume for definitive radiation therapy in patients with locoregionally recurrent nonsmall-cell lung cancer after surgical resection. Clin Lung Cancer. 2013;14:399-406.

18. Kim E, Song C, Kim MY, Kim JS. Long-term outcomes after salvage radiotherapy for postoperative locoregionally recurrent non-small-cell lung cancer. Radiat Oncol J. 2017;35:55-64.

19. Seol KH, Lee JE, Cho JY, Lee DH, Seok Y, Kang MK. Salvage radiotherapy for regional lymph node oligo-recurrence after radical surgery of non-small cell lung cancer. Thorac Cancer. 2017;8:620-9.

20. Okawara G, Mackay JA, Evans WK, Ung YC; Lung Cancer Disease Site Group of Cancer Care Ontario's Program in Evidence-based Care. Management of unresected stage III nonsmall cell lung cancer: a systematic review. J Thorac Oncol. 2006;1:377-93.

21. O'Rourke N, Roqué I Figuls M, Farre Bernado N, Macbeth F. Concurrent chemoradiotherapy in non-small cell lung cancer. Cochrane Database Syst Rev. 2010;(6):CD002140.

22. van Tinteren $H$, Hoekstra OS, Smit EF, van den Bergh JH, Schreurs AJ, Stallaert RA, et al. Effectiveness of positron emis- sion tomography in the preoperative assessment of patients with suspected non-small-cell lung cancer: the PLUS multicentre randomised trial. Lancet. 2002;359:1388-93.

23. Bar-Shalom R, Yefremov N, Guralnik L, Gaitini D, Frenkel A, Kuten A, et al. Clinical performance of PET/CT in evaluation of cancer: additional value for diagnostic imaging and patient management. J Nucl Med. 2003;44:1200-9.

24. Berghmans T, Dusart M, Paesmans M, Hossein-Foucher C, Buvat I, Castaigne $\mathrm{C}$, et al. Primary tumor standardized uptake value (SUVmax) measured on fluorodeoxyglucose positron emission tomography (FDG-PET) is of prognostic value for survival in non-small cell lung cancer (NSCLC): a systematic review and meta-analysis (MA) by the European Lung Cancer Working Party for the IASLC Lung Cancer Staging Project. J Thorac Oncol. 2008;3:6-12.

25. Paesmans M, Berghmans T, Dusart M, Garcia C, HosseinFoucher C, Lafitte JJ, et al. Primary tumor standardized uptake value measured on fluorodeoxyglucose positron emission tomography is of prognostic value for survival in non-small cell lung cancer: update of a systematic review and metaanalysis by the European Lung Cancer Working Party for the International Association for the Study of Lung Cancer Staging Project. J Thorac Oncol. 2010;5:612-9.

26. Jimenez-Bonilla JF, Quirce R, Martinez-Rodriguez I, Banzo I, Rubio-Vassallo AS, Del Castillo-Matos R, et al. Diagnosis of recurrence and assessment of post-recurrence survival in patients with extracranial non-small cell lung cancer evaluated by 18F-FDG PET / CT. Lung Cancer. 2013;81:71-6.

27. Dosoretz DE, Galmarini D, Rubenstein JH, Katin MJ, Blitzer $\mathrm{PH}$, Salenius SA, et al. Local control in medically inoperable lung cancer: an analysis of its importance in outcome and factors determining the probability of tumor eradication. Int J Radiat Oncol Biol Phys. 1993;27:507-16.

28. Kong FM, Ten Haken RK, Schipper MJ, Sullivan MA, Chen M, Lopez C, et al. High-dose radiation improved local tumor control and overall survival in patients with inoperable/unresectable non-small-cell lung cancer: long-term results of a radiation dose escalation study. Int J Radiat Oncol Biol Phys. 2005;63:324-33.

29. Bradley JD, Paulus R, Komaki R, Masters G, Blumenschein G, Schild $S$, et al. Standard-dose versus high-dose conformal radiotherapy with concurrent and consolidation carboplatin plus paclitaxel with or without cetuximab for patients with stage IIIA or IIIB non-small-cell lung cancer (RTOG 0617): a randomised, two-by-two factorial phase 3 study. Lancet Oncol. 2015;16:187-99.

30. Jegadeesh N, Liu Y, Gillespie T, Fernandez F, Ramalingam S, Mikell J, et al. Evaluating intensity-modulated radiation therapy in locally advanced non-small-cell lung cancer: results from the national cancer data base. Clin Lung Cancer. 2016; 17:398-405. 